\title{
KAJIAN KUAT TARIK SAMBUNGAN LIMBAH BOTOL PLASTIK \\ DENGAN BERAGAM VARIASI BENTUK SISI KAYU
}

\author{
ABSTRAK \\ Agustin Poncowati ${ }^{1}$, Taufiq Lilo Adi Sucipto ${ }^{2}$, Anis Rahmawati $^{3}$ \\ agustin20@gmail.com
}

Potongan-potongan kayu sisa bangunan merupakan limbah yang sangat banyak dan mudah ditemukan di lingkungan. Limbah kayu ini dapat digunakan kembali dengan menggunakan alat sambung. Limbah botol plastik dapat digunakan sebagai alat sambung dengan cara dipanaskan pada suhu tertentu agar dapat melekat pada kayu. Agar terjadi lekatan yang baik, diperlukan bentuk kayu yang tidak rata sebagai tempat lekatan. Penelitian ini membatasi pada kuat tarik sejajar serat dan bertujuan untuk mengetahui apakah terdapat perbedaan yang signifikan pada kekuatan sambungan dengan beragam variasi bentuk sisi kayu dan untuk mengetahui bentuk sisi kayu dengan kekuatan terbaik. Sambungan ini berbentuk butt joint (sambungan tegak) dengan diberikan 4 buah variasi bentuk sisi berupa pemberian coakan dan alur. Penelitian ini menggunakan metode kuantitatif dengan pendekatan eksperimen dan analisis data menggunakan analisis anova one way. Pengambilan sampel dilakukan dengan sampling jenuh yaitu sebanyak 24 buah sampel. Masing-masing variasi terdiri dari 6 buah sampel. Hasil pada penelitian ini menunjukkan bahwa terdapat perbedaan yang signifikan pada kuat tarik sejajar serat dari 4 variasi bentuk sisi kayu. Bentuk sisi kayu yang menghasilkan kuat tarik sejajar serat tertinggi adalah 2 buah alur pada setiap sisi.

Kata kunci : kuat tarik kayu, limbah botol plastik, sambungan kayu

\begin{abstract}
Pieces of wood as building waste material were much and easy to found in the environment. Wood waste could reuse using connector. This connector was plastic bottle waste heated at specific temperature to make adhesive from wood. The adhesive could operate well if there is irregular side shape to result better of its strength. The study focused on tensile strength parallel to its fiber and aimed to investigate whether there is significant difference of the strength from 4 variants of side shape and to investigate the side shape with the best tensile strength. The wood joint used butt joint with 4 variants of its shape, they were groove and notch. This study used quantitative method with experimental study and one way anova as its analyze technique. The sampling used saturated sampling with 24 samples, they are 6 samples each. The research has shown that there is significant difference of wood strength from 4 variants of side shape. The side shape with the best result in tensile strength is 2 groove every side.
\end{abstract}

Keywords: wood tensile strength, plastic bottle waste, wood joint

\footnotetext{
${ }^{1}$ Mahasiswa Program Studi Pendidikan Teknik Bangunan FKIP Universitas Sebelas Maret

${ }^{2}$ Pengajar Program Studi Pendidikan Teknik Bangunan FKIP Universitas Sebelas Maret

${ }^{3}$ Pengajar Program Studi Pendidikan Teknik Bangunan FKIP Universitas Sebelas Maret
} 


\section{PENDAHULUAN}

Green building adalah bentuk kepedulian para ahli di bidang konstruksi terhadap kelestarian lingkungan yang dapat berkonstribusi untuk menahan laju pemanasan global (Dianita, Sucipto, \& Sutrisno, 2014:2). Rancangan bangunan ini tidak hanya mengenai manajemen penghematan energi dan pengelolaan limbahnya, namun juga pemanfaatan material bahan bangunan yang tidak akan membahayakan lingkungan baik jangka pendek maupun jangka panjang. Salah satu kriteria bangunan ramah lingkungan berdasarkan GBCI (Green Building Council Indonesia) adalah penggunaan material bekas.

Sektor konstruksi menghasilkan banyak limbah diantaranya adalah limbah kayu. Limbah kayu dapat berupa potongan kayu baru maupun bekas bangunan lama. Untuk dapat memanfaatkan limbah tersebut, diperlukan sebuah alat sambung. Alat sambung yang tergolong limbah yang dapat digunakan adalah limbah botol plastik.

Botol plastik dari jenis PET (Polyethylene Terephthalate), menurut Elipso (2012) dalam Orset, dkk (2017:1) sebanyak 389 juta botol PET telah diproduksi dengan $46 \%$ nya adalah dari produk air minum. Selain itu, angka pertumbuhan permintaan terhadap minuman kemasan plastik terus meningkat hingga sebesar $7 \%$ di Indonesia (Pratomo, 2016:1).

Limbah botol plastik butuh waktu yang sangat lama untuk terurai di lingkungan. Selain sulit diurai, teknologi untuk mengolah limbah botol plastik masih minim. Sehingga limbah botol plastik sangat perlu untuk dimanfaatkan, salah satunya sebagai alat sambung kayu.

Alat sambung limbah botol plastik dibuat dengan menggunakan sebuah alat bernama hot gun untuk memanaskan plastik PET yang meleleh pada temperatur $300^{\circ} \mathrm{C}$ hingga molekul plastik saling bergerak mendekat membentuk sebuah sambungan yang kuat (Tucker, 2016:1). Alat sambung ini pertama kali dipamerkan pada tahun 2016 oleh Micaella Pedros, seorang seniman asal London. Micaella pedros membuat bentuk sisi kayu yang tidak rata agar plastik dapat melekat pada kayu.

Penelitian ini dimaksudkan untuk mengetahui apakah ada perbedaan yang signifikan pada kuat tarik sejajar serat dari 4 variasi bentuk sisi kayu dan untuk mengetahui bentuk sisi kayu seperti 
apakah yang mampu memberikan kekuatan tarik sejajar serat terbesar.

Bentuk sisi kayu merupakan bentuk penampang dari kayu untuk meningkatkan kekuatan kayu (Yoresta \& Sidiq, 2016:28). Bentuk sisi yang tidak rata tersebut biasanya akibat adanya coakan atau alur. Coakan maupun alur disini hanya untuk memudahkan penamaan. Pada prinsipnya keduanya memberikan bentuk sisi yang tidak rata pada kayu.

Coakan merupakan suatu bentuk lubang yang terletak di ujung setiap sisi kayu. Sedangkan alur merupakan suatu bentuk lubang yang terletak di sepanjang permukaan kayu. Bentuk dari coakan adalah setengah bola sedangkan bentuk dari alur adalah setengah tabung. Baik alur maupun coakan pada penelitian ini berfungsi sebagai tempat agar plastik melekat lebih kuat pada kayu.

"Menurut Pedros, kekuatan sambungan plastik bergantung pada bentuk objek yang disambungkan dan alur pada kayu. Semakin dalam coakan menyebabkan plastik membentuk hubungan yang kuat dan mencegah dari bergeraknya bagian-bagian yang disambung dan lemahnya sambungan" (Tucker, 2016:1).
Pemberian variasi bentuk sisi yang tidak rata pada penelitian ini diharapkan mendapatkan perbedaan yang signifikan pada kekuatan ke empat variasi, selain itu ada bentuk sisi kayu tertentu yang memberikan kekuatan tarik terbesar.

\section{METODE PENELITIAN}

Pengujian pada penelitian ini adalah uji tarik sejajar serat berdasarkan SNI 03-3958-1995. Sampel yang digunakan sebanyak 6 buah pada setiap variasi untuk masing-masing pengujian dengan jenis kayu adalah kayu jati berukuran $2,5 \times 2,5 \times 46 \mathrm{~cm}$. Total sampel yang digunakan adalah 48 buah.

Botol yang digunakan adalah jenis PET sebanyak 1 lapis dengan panjang $15 \mathrm{~cm}$ dan terletak di tengah bagian kayu yang disambung.

Teknik pengambilan sampel adalah dengan sampling jenuh dimana seluruh anggota populasi sebagai sampel dengan variabel bebas berupa variasi bentuk sisi kayu yang dapat dilihat pada gambar 1. Variabel terikat pada penelitian ini berupa kuat tarik sejajar serat. 


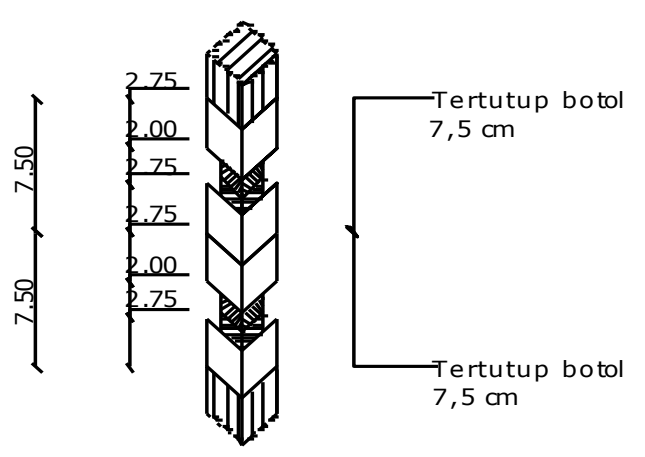

Tipe A (1 alur tiap sisi)

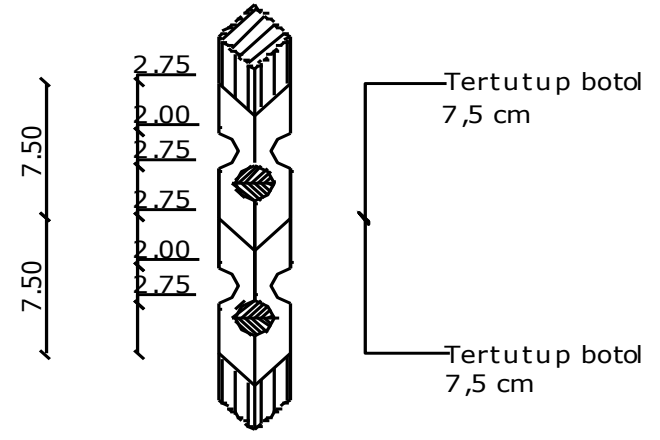

Tipe B (1 coakan tiap sisi)

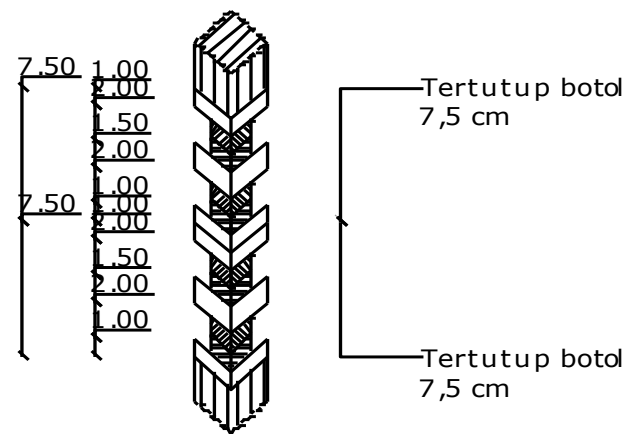

Tipe C (2 alur tiap sisi)

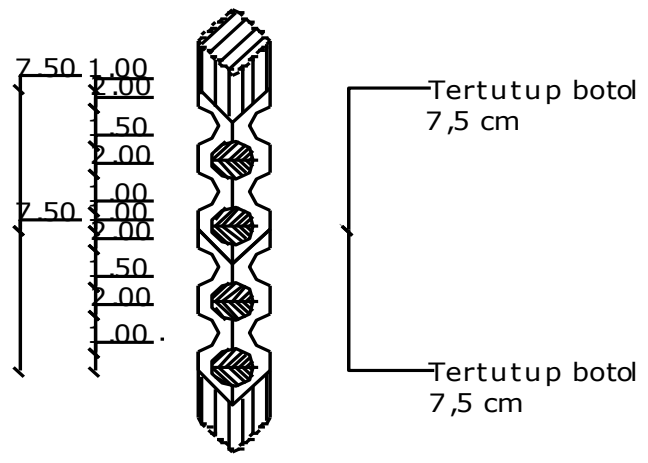

Tipe D (2 coakan tiap sisi)

Gambar 1. Variasi bentuk sisi kayu untuk uji tarik
Uji kadar air dilakukan agar syarat pengujian terpenuhi. Kadar air maksimal untuk uji kuat tarik adalah 20\%. Perhitungan kadar air menggunakan rumus 1 berikut:

$\mathrm{MC}=\frac{(A-B)}{B} \times 100 \%$

$\mathrm{MC}=$ kadar air kayu $(\%)$

$\mathrm{A}=$ berat benda uji sebelum dioven $(\mathrm{g})$

B = berat benda uji setelah dioven $(\mathrm{g})$

Apabila kadar air telah memenuhi, kayu berukuran 3,5x3,5 dipotong-potong menjadi $23 \mathrm{~cm}$ sebanyak 48 buah untuk sambungan limbah botol plastik, 6 buah untuk sambungan lem, dan 5 buah kayu utuh sepanjang $46 \mathrm{~cm}$.. Kayu bagian tengah dikurangi dimensinya menjadi $2,5 \times 2,5$ $\mathrm{cm}$ sehingga menyisakan $10 \mathrm{~cm}$ untuk pegangan dengan dimensi $3,5 \times 3,5 \mathrm{~cm}$ seperti pada Gambar 2.

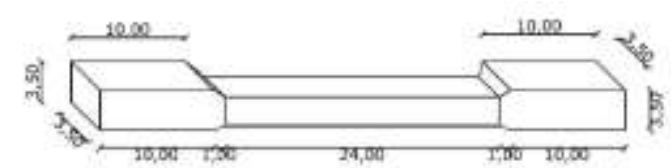

Gambar 2. Kayu Sebelum Pemberian Variasi Bentuk Sisi

Kayu tersebut kemudian diberikan variasi bentuk sisi seperti pada gambar 1. Selanjutnya botol plastik yang telah dipasang pada kayu yang disambung diletakkan di tengah bentang kemudian dipanaskan dengan hot air gun 
selama 3-7 menit hingga plastik melekat erat pada kayu.

Melekatnya plastik pada kayu dilihat dari tidak adanya rongga udara pada benda uji. Sedangkan untuk bagian coakan maupun alur yang permukaanya tidak rata harus dipastikan bahwa tidak ada benjolan.

Pada pembuatan benda uji sambungan lem, kayu direkatkan menggunakan lem epoxy yaitu campuran lem epoxy hardener dan resin dengan pengeringan selama 24 jam. Sedangkan untuk benda uji kayu utuh, kayu tidak diberikan perlakuan sama sekali sebelum diuji.

Benda uji yang telah siap duji dapat dilihat pada Gambar 3 untuk uji tarik. Benda uji kemudian diuji menggunakan mesin UTM (Universal Testing Machine).
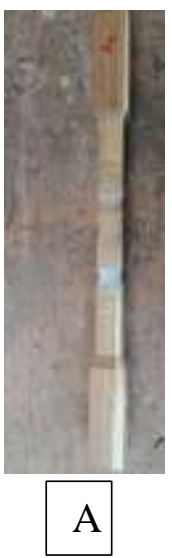
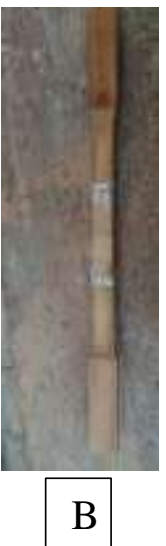
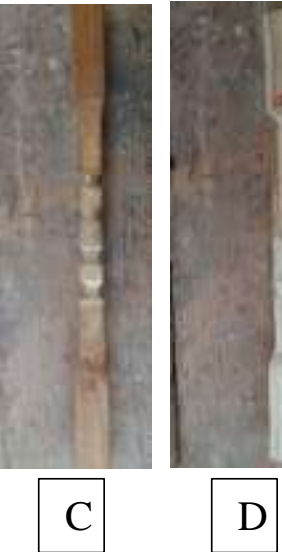

Gambar 3. Benda Uji Tarik

Setelah pengujian, didapatkan data berupa maximum load atau beban maksimal yang diterima benda uji (P). Selanjutnya menghitung kuat tarik sejajar serat menggunakan rumus 2 .

$\mathrm{ft} / /=\frac{P}{b \times h}$

Keterangan :

$\mathrm{f}_{\mathrm{t} / /}=$ kuat tarik sejajar serat $\left(\mathrm{kgf} / \mathrm{cm}^{2}\right)$

$\mathrm{P}=$ beban uji maksimum (kgf)

$\mathrm{b}=$ lebar benda uji $(\mathrm{cm})$

$\mathrm{h}=$ tinggi benda uji $(\mathrm{cm})$

Data yang didapatkan dari pengujian selanjutnya diolah dengan melakukan deteksi outlier yaitu membersihkan data dari data outlier. Data outlier pada penelitian ini adalah data yang memiliki $z$-score diluar range untuk data kurang dari 80 yaitu $-2,5$ hingga 2,5 (Basuki \& Yuliadi, 2015:84).

Apabila ditemukan data outlier, maka data tersebut harus dibuang karena tidak dapat digunakan. Data ini kemudian dianalisis dengan menggunakan analisis varians satu arah (anova one way) melalui SPSS. Sebagai prasyarat analisis, dilakukan juga uji normalitas dan homogenitas, serta dipastikan bahwa sampel yang diambil saling bebas (independen).

\section{HASIL PENELITIAN}

Pengujian kadar air berdasarkan SNI 03-6850-2002 menghasilkan ratarata kadar air 15,9\%. Kadar air tersebut 
telah memenuhi persyaratan pengujian tarik.

Kuat relatif merupakan kekuatan kayu dibandingkan dengan kayu utuh. Hasil uji tarik sejajar serat dapat dilihat pada Tabel 1 .

Tabel 1. Hasil Uji Tarik Sejajar Serat

\begin{tabular}{lrr}
\hline $\begin{array}{c}\text { Variasi } \\
\text { Bentuk Sisi } \\
\text { Kayu }\end{array}$ & $\begin{array}{c}\text { Rata-rata } \\
\mathbf{f t} / / \\
\left(\mathbf{k g f} / \mathbf{c m}^{\mathbf{2}}\right)\end{array}$ & $\begin{array}{c}\text { Kuat } \\
\text { Relatif } \\
(\boldsymbol{\%})\end{array}$ \\
\hline A (1 alur) & 7,68 & 1,81 \\
B (1 coakan) & 6,59 & 1,56 \\
C (2 alur) & 11,00 & 2,60 \\
D (2 coakan) & 9,02 & 2,13 \\
Kayu utuh & 423,43 & 100 \\
Sambungan & 49,74 & 11,75 \\
Lem & & \\
\hline
\end{tabular}

\section{PEMBAHASAN}

Pada saat pengujian didapati kerusakan pada bagian sambungan yaitu plastik terlepas dari kayu seperti pada Gambar 4. Kerusakan yang terjadi pada sambungan menunjukkan lemahnya kekuatan sambungan (Widyawati, 2009:85).

Pada penelitian ini, bentuk sambungan adalah sambungan tegak. Bentuk sambungan tegak merupakan bentuk sambungan yang paling lemah terhadap beban tarik apabila dibandingkan dengan bentuk sambungan miring dengan kemiringan berapapun variasinya (Widyawati, 2009:85).

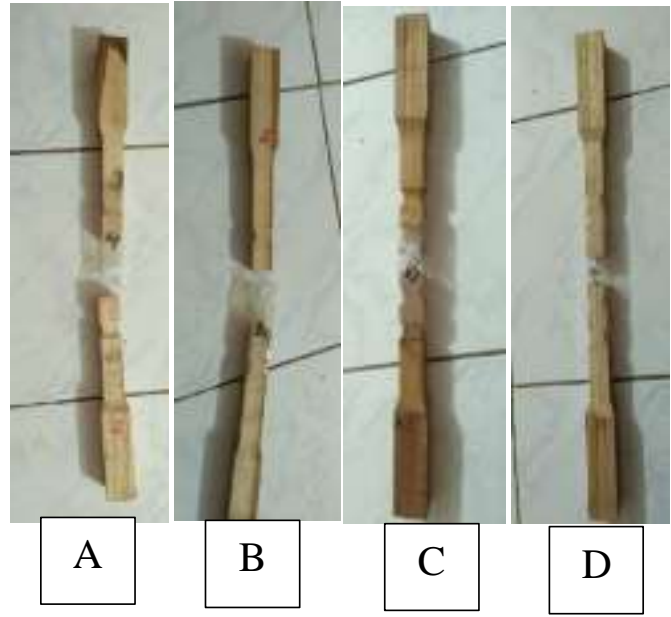

Gambar 4. Benda Uji Tarik Pasca

Pengujian

Baik sambungan lem maupun sambungan limbah botol plastik pada penelitian ini, memiliki kuat tarik yang sangat kecil seperti terlihat pada Gambar 5. Kuat tarik sambungan lem hanya mencapai $11,75 \%$ dari kayu utuh sedangkan sambungan limbah botol plastik terbesar hanya mencapai $2,6 \%$. Hal ini dikarenakan bentuk sambungan merupakan butt joint (Sambungan tegak).

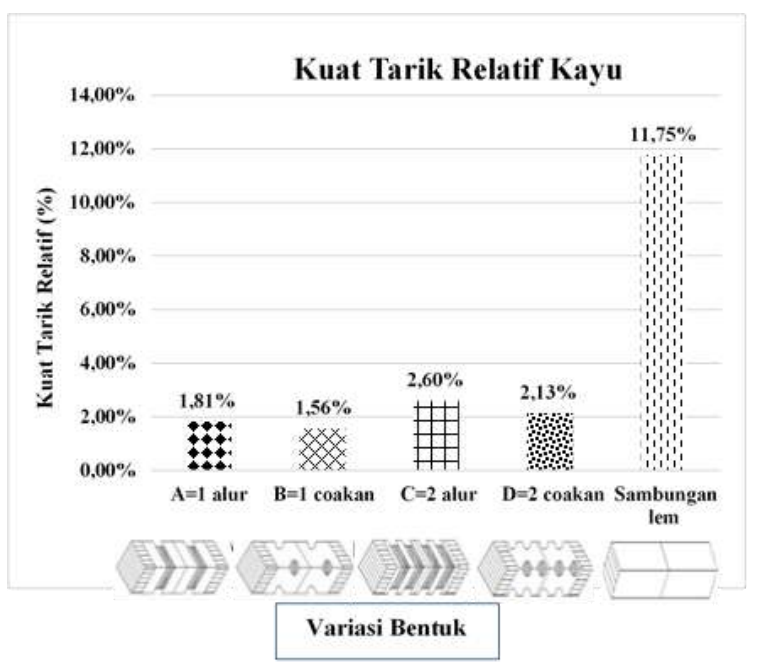

Gambar 5. Kuat Tarik Relatif 
Pemberian coakan ataupun alur dengan jumlah yang lebih banyak pada setiap sisi mampu memberikan hasil kuat tarik sejajar serat yang lebih baik. Dari Gambar 5 dapat diketahui bahwa baik alur maupun coakan, apabila jumlah bentuk sisi yang tidak rata semakin banyak, maka semakin menghasilkan kuat tarik sejajar serat yang lebih besar.

Apabila disusun urutan berdasarkan nilai kuat tarik sejajar serat tertinggi, maka urutan pertama adalah sambungan lem, bentuk sisi kayu berupa adanya 2 buah alur pada setiap sisi (tipe C), kemudian 2 buah coakan (tipe D), 1 buah alur (tipe A), kemudian 1 buah coakan (tipe B).

Jumlah (n) bentuk sisi yang tidak rata berupa coakan maupun alur menambah kekuatan tarik sambungan limbah botol plastik. Hal ini dikarenakan bentuk sisi kayu yang tidak rata berfungsi sebagai shear connector atau lekatan (Yoresta \& Sidiq, 2016:28).

Dari analisa dan penjelasan diatas, dapat disimpulkan bahwa pemberian variasi bentuk coakan memberikan pengaruh berupa bertambahnya kekuatan tarik kayu. Meskipun kekuatan tarik tersebut masih sangat jauh dari kekuatan tarik kayu utuh dikarenakan bentuk sambungan yang kurang baik untuk menahan tarik yaitu sambungan tegak.

\section{KESIMPULAN}

Penelitian ini menghasilkan kesimpulan bahwa terdapat perbedaan yang signifikan pada nilai kuat tarik sejajar serat sambungan kayu dengan alat sambung limbah botol plastik pada 4 variasi bentuk sisi kayu. Selain itu, variasi bentuk sisi kayu tipe $\mathrm{C}$ berupa adanya 2 buah alur pada setiap sisi memberikan kuat tarik sejajar serat terbesar yaitu $11 \mathrm{kgf} / \mathrm{cm}^{2}$.

\section{SARAN}

Dari penelitian ini, terdapat beberapa saran yang perlu disampaikan penulis, diantaranya adalah perlunya standar pemanasan botol plastik dengan menggunakan hot air gun pada saat pembuatan benda uji dan perlunya diadakan pembandingan kekuatan sambungan limbah botol plastik dengan bentuk yang sama yaitu butt joint tanpa adanya variasi bentuk sisi kayu.

Agar mendapat kuat tarik yang baik, sambungan limbah botol plastik perlu digabungkan dengan sambungan lain seperti sambungan lem dengan bentuk sambungan adalah sambungan miring atau dengan menambahkan 
takikan serta menambah jumlah bentuk sisi yang tidak rata pada setiap sisi.

\section{UCAPAN TERIMAKASIH}

Penulis mengucapkan terimakasih kepada bapak Taufiq Lilo Adi S, S.T., M.T, ibu Anis Rahmawati, S.T., M.T., yang telah menjadi pembimbing dalam melakukan penelitian, dan Tim sambungan limbah botol plastik.

\section{DAFTAR PUSTAKA}

Basuki, A. T., \& Yuliadi, I. (2015). Electronic Data Processing (SPSS 15 dan EVIEWS 7). Yogyakarta: Danisa Media.

Dianita, R., Sucipto, T. L. A., \& Sutrisno. (2014). Analisa Pemilihan Material Bangunan Dalam Mewujudkan Green Building (Studi Kasus: Gedung Kantor Perwakilan Bank Indonesia Solo). Pendidikan Teknik Bangunan, 4(4). Diambil dari

http://jurnal.fkip.uns.ac.id/index. $\mathrm{php} / \mathrm{ptb} /$ article/view/3350

Handayani, S. (2009). Metode Perekatan Dengan Lem Pada Sambungan Pelebaran Kayu. Jurnal Teknik Sipil \& Perencanaan UNNES, Vol. 11, 11-20.

Orset, C., Barret, N., \& Lemaire, A. (2017). How consumers of plastic water bottles are responding to environmental policies? Waste Management. https://doi.org/10.1016/j.wasma n.2016.12.034

Pratomo, H. B. (2016). 5 Negara pengguna botol plastik terbesar dunia termasuk Indonesia.
Diambil 24 September 2016, dari https://www.merdeka.com/uang/ 5-negara-pengguna-botolplastik-terbesar-dunia-termasukindonesia.html

Purnamasari, P. E., \& Suryaman, F. (2010). Pengaruh Penggunaan Limbah botol plastik sebagai bahan tambah terhadap karakteristik Lapis Aspal Beton (Laston). Prociding of Konferensi Nasional Teknik Sipil 4. Sanur. Diambil dari http://ft.uajy.ac.id/wpcontent/uploads/2015/12/I45Eliza_397-404_.pdf

Tucker, E. (2016). Micaella Pedros uses shrunk plastic bottles to join furniture. Diambil 16 Februari 2017, dari https://www.dezeen.com/2016/0 6/30/micaella-pedros-royalcollege-of-art-graduate-showrcajoining-bottles-wood-furniturerecycled-plastic/

Wang, D.-Y. (2017). Novel fire retardant polymers and composite materials. Diambil dari http://lib.myilibrary.com?id=949 496

Widyawati, R. (2009). Perbandingan Kekuatan Butt Joint Dan Scarf Joint Pada Kayu Dengan Alat Sambung Perekat. Jurnal Rekayasa, 13(1), 81-91. Diambil dari http://ftsipil.unila.ac.id/ejournals/index. php/jrekayasa/article/view/40

Yoresta, F. S., \& Sidiq, M. I. (2016). Pengaruh Variasi Bentuk Kombinasi Shear Connector Terhadap Perilaku Lentur Balok Komposit Beton-Kayu. Jurnal Rekayasa Sipil (JRS-Unand), 12(2). Diambil dari http://jrs.ft.unand.ac.id/index.ph p/jrs/article/view/v12-n2-yoresta 